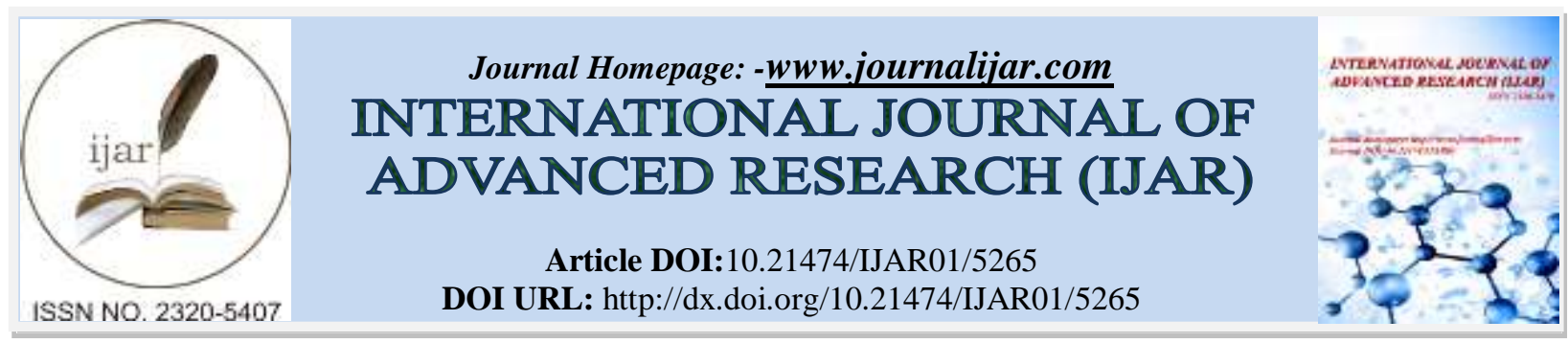

RESEARCH ARTICLE

\title{
ISOLATION OF ACTINOBACILLUS ACTINOMYCETUMCOMITANS (AGGREGOBACTER) ANDPORPHYROMONAS GINGIVALIS FROM SUDANESE AGGRESSIVE PERIODONTITIS PATIENTS AND TESTING INHIBITORY EFFECT OF GARLIC EXTRACT COMPARED TO CHLORHEXIDINE DIGLUCONATE $0.2 \%$.
}

Awatif Hassan Mohamed.

Al Neelain university department of community dentistry faculty of dentistry, Khartoum, Sudan- PO..Box 12702.

\section{Manuscript Info}

Manuscript History

Received: 24 June 2017

Final Accepted: 26 July 2017

Published: August 2017

\section{Abstract}

Aggressive periodontitis is a destructive inflammatory condition affecting the investing and supporting tissues of the teeth. Detectable levelsof Porphyromonasgingivalis, $T$.forthia, Prevotellainetrmedia, Campylobacter and ActinobacillusActinomycetnsemcomita are associated with disease progression ,Adjunct use of antimicrobial agents was implemented for the treatment of the diseaseand also someantiseptic mouth wash like chlorhexidinedigluconate $0.2 \%$. Now a day's ,medicinal plants are usedas antimicrobial against bacteria due to increase of bacterial resistant to antibiotics, so Garlic (Allium sativum) used as antimicrobial, antifungal and antiviral against oral pathogens. So the aim of the present study was to isolateActinobacillusactinomycetumcomitansandPorphyromonasgingiv alis,from Subgingival fluid of Sudanese aggressive periodontitis patients and tostudy the effect of water garlic extract against the isolate compared to chlorhexidinedigluconate $0.2 \%$.

Copy Right, IJAR, 2017,. All rights reserved.

\section{Introduction:-}

Thirty aggressive periodontitis patients were recruited from patients attending Khartoum Teaching Dental Hospital after written approval. Patients gave verbal consent for clinical examination, age range 18-35 years. Patients examined for plaque index (PLI), Gingival Index (GI), Probable pocket depth and attachment loss in mm.

Microbiologically: Sub-gingival plaque samples were obtained from two deepest sites per quadrant for each patient for identification of the major causative micro-organismsActinobacillusactinomycetumcomitans, andProphronomonasgingivalis. Identification was done by culture . Garlic extract was subjected to preliminary antimicrobial screening using the cup-plate diffusion method against the detected bacteria. The Minimum inhibitory concentration $(M I C)$ of the garlic extract was determined, Chlorhexidinedigluconate $0.2 \%$ used as positive control and distilled water as negative control (invitro study). Zones of inhibitions were measured and averaged the mean diameter of the zone of inhibition in mm was compared to the zone of inhibition of chlorhexidine using Pearson correlation test to identify if there is a statically difference between garlic extract and chlorhexidinedigluconate $0.2 \%$. Correlation is significant at the 0.01 and 0.05 level ( 2 tailed)

Results: There was an increase in plaque index, gingival index, pocket depth and loss of attachment among aggressive periodontitis patients. Actinobacillusactinomycetumcomitanswas not detected (negative) but 
Porphyromonasgingivalis detected in $70 \%$ of the sample There was growth inhibition of Porphyromonasgingivalisby water garlic extract compared to chlorhexidinedigluconate $0.2 \%$ there was no statistical significance difference between the means $* *$ Correlation is significant at the 0.01 level ( 2 tailed). Pearson correlation of Garlic and chlorhexidinedigluconate $=0.596$ and $\mathrm{P}$-Value $=0.069$

\section{Conclusion:-}

The present study indicates that garlic extract has the same effect of chlorhexidinedigluconate $0.2 \%$ against Porphyromonasgingivalis, so it may have therapeutic value in prevention and treatmentof aggressive periodontitis. So garlic extract can be used in well designed clinical trial in form of mouth wash for prevention and treatment of aggressive periodontitis,

Key words: Garlic; Chlorhexidinedigluconate $0.2 \%$; Oral bacteria; Porphyromonasgingivalis.

\section{Introduction:-}

Aggressive periodontitis is destructive inflammatory condition affecting the investing and supporting tissues of the teeth. It is classified into localized and generalized form. (1) Detectable levelsof Porphyromonasgingivalis, $T$ .forthia, Prevotellainetrmedia, Campylobacter and ActinobacillusActinomycetnsemcomita are associated with disease progression and their elimination by therapy is associated with an improvement in the clinical signs of the disease. $(2,3)$ Both Porphyromonasgingivalis and ActinobacillusActinomycetnsemcomita are known to invade host tissue cells which may be significant in more aggressive forms of adult periodontitis.(4)A.actinomycetemcomitansare gram-negative bacilli which are small to coccoid on solid media. Bipolar staining on Gram stain may occur. Growth in culture is slow and requires $2-7$ days, the organism grows on enriched media such as blood or chocolate agar, and prefers 5-10\% CO2 atmosphere. Selective media have been described, but are not used routinely. Colonies ofActinobacillusActinomycetnsemcomita are small at 24 hours, with an opaque dot at the center of the colony, which will develop into a star-like shape on prolonged incubation. Important characteristics leads to proper identification include the Gram stain morphology, slow growth, negative oxidase and positive catalase results, negative spot indole results, and the ability to ferment glucose but not lactose. The oxidase test of the isolate reported as weakly positive by some laboratories, a characteristic which is present in up to $19 \%$ of strains, and makes the distinction from closely related species, particularly Pasteurellaand catalasepositive Haemophilusspecies difficult. A actinomycetemcomitansis closely related to $H$. aphrophilusand $H$. paraphrophilus, but previous proposals to transfer this organism to the Haemophilusgenus were rejected.(5,6 )Porphyrmonoasgingivalis belongs to the genera porphymonoas from family bacteroidacese, these bacteria are darkpigmented gram-negative strict anaerobic cocobacilli, they grow in culture media forming convex, smooth glossy colonies of 1-2 mm diameter, which demonstrate a progressive darkening in the center , because production of protoheme,the substance responsible typical color of these colonies. For identification culture plated on Brucella (Oxoid) 5\% Sheep Blood Agar with Vitamin K and Hemin,plates were cultivated in anaerobic atmosphere at $37^{\circ} \mathrm{C}$ for $48 \mathrm{~h}$ and to obtain pure culture black pigmented colonies were recultivated at the same conditions and then a biochemical test was performed. (White and Myrand1981)(7) the major virulence factors ofprophyrmonasgingivalis is Lys-gingipain a lysine-specific cysteine proteinase, which interferes with both cellmatrix and cell-cell adhesion, fimbriae of Porphyromonasgingivalis plays an important role in its adhesion to and invasion of host cell and has effect on periodontal ligaments cells through a cooperative action of gingipains. (8, 9, 10) There are many trials to use vaccine against prophyrmonasgingivalis to aid in prevention of periodontitis in animals but it is still trials. $(11,12)$ The treatment of aggressive periodontitis in addition to plaque control and debridement, adjunctive treatment of aggressive include the use of systemic antibiotics e.g tetracycline oral capsules or by tetracycline fiber therapy, monocycline and mitronidazole $(13,14,15,16)$.Some antiseptic mouth wash used after scaling and root planning and after surgical treatment, like Octenidine and Chlorhexidinegluconate $0.2 \%$ which is used as mouthwash or gel instead of toothpaste. Chlorhexidinegluconate has many disadvantages of staining the teeth, it has powerful taste, suppress normal sense of taste in few people, irritant to the oral tissues and may produce sore lips $(17,18)$. Also ozonated water used as antimicrobials in the treatment of periodontitis patients (19).With increase of bacterial resistant to antibiotic medicinal plants is applied widely for the treatment of many diseases, one of these plants is garlic which was used as an antimicrobial agent due to presence of allicin (sulpher compound) called thiosulphonate, the plant use allicin as antimicrobial against invaded bacteria or single cell pathogen(.(20.21). Garlic used in different forms, powder, oil and heated garlic which has antimicrobial effect on Staphylococcus aurous B33. Garlic compound were used as , antiviral, antifungal and antiprotozoal, it has antibacterial effect on Escherichia Salmonela, Staphylococcus, Streptococcus, Klebsiella, Proteus and Mycobacterium. $(22,23,24$ ) Allicin showed synergistic effect when combines with a antibiotics which may overcome the resistance of micro-organisms .(25) In dentistry, garlic used as antimicrobial against oral bacteria in 
the form of mouth wash which have inhibitory effect against Gram-positive, Gram-negative organisms and fungi by reducing bacterial counts. (26) In some studies tea tree oil, garlic, might be an alternative to chlorhexidine solutions against oral microorganisms. $(27,28)$ Filter sterilized, aqueous extract of garlic has the ability to inhibit the growth of gram positive and gram negative micro-organisms and it has action against the arg and lys-gingipains activity of P.gingivalis and it has activity against multidrug-resistant (MDR) strains of Streptococcus mutans isolated from human carious teeth and inhibit $P$. gingivalis protease activity.((29,30,31,32). Garlic extracts in concentrations of $12.5 \%$ is cytotoxic to human gingival fibroblasts but it is safe at $6.25,3.12$, and $1.5 \%$, the high concentration of garlic is less cytotoxic than chlorhexidinedigluconate. (33) In Sudan there are many studies on the prevalence of aggressive periodontitis among different age groups, the A. actinomycetemcomitan were detected in the subgingival plaque of $12(70.6 \%)$ patients with aggressive periodontitis and from only one (5.9\%) control subject, showing a significantly higher frequency of detection in cases than in controls. The JP2 clone of A. actinomycetemcomitans was not detected in the subgingival plaque of high school subjects in Sudan. The detection of non-JP2 types of A. actinomycetemcomitans may be a useful marker of increased risk for development of aggressive periodontitis in young subjects. (34)

so the present study was designed to investigate the periodontal health of the aggressive periodontitis patients including determination of major causative micro-organisms, Actinobacillusactinomycetumcomitansand,porphyromonasgingivalis and to test the effect of a garlic extract on their inhibition compared to chlorhexidine $0.2 \%$ ( in invitro study).

\section{Material and method:-}

Cross-sectional analytical clinical and microbiological hospital based study at Department of Periodontology Faculty of Dentistry, University of Khartoum. Thirty aggressive periodontitis patients both males and females Patients were within the age group 18-35 years(,mean $25.4 \pm 5.5$ years) newly diagnosed according to clinical and radiographic examination as aggressive periodontits patients For all participants the clinical examination was done using a mouth mirror and periodontal probe (Universityof Michigan-0 probe) for 10 teeth recorded in special form ,The patients were examined for plaque accumulation according to PLI (Sillness and Loe)(,35) examination of gingivitis according to GI (Loe and Sillness)(36), in addition to measuring pocket depth and loss of attachment in $\mathrm{mm}$ for the deepest site of the examined teeth. Panoramic X-rays or priapical were done for all patients. Patients excluded if they had systemic diseases, those who were immunocompromised, pregnant ladies, patients used antibiotics 3 months before the examination and patients who had periodontal treatment 3 months before the start of the study.

\section{Ethical approval:-}

Ethical clearance was given by the Research Committee (Faculty of Medicine/ University of Al-Neelain 2007) and approval from the director of faculty of dentistry, head department of periodontology for sample collection. Since the patient are adult, seeking periodontal treatment and capable of giving informed consent, voluntary and freely they agrees verbally to participate in the study after explanation of the aim of the study .

\section{Bacterial isolate:-}

Isolation of Actinobacillusactinomycetumocomitans:

Bacterial suspension was vortex and homogenized and incubated anaeropically with cooked meat media. To obtain pure culture Samples were subcultured in blood agar with vancomycin $5 \mathrm{Mg} / \mathrm{ml}$ and incubated anaerobically in anaerobic gar at $37 \mathrm{C}^{\circ}$ using gas generating kits for carbon dioxide (Micromaster LaboratoriesPVT. LTD38/39, KalpataruInd Estate, Thane (W) MAH. INDIA.

\section{Isolation of prophyromonasegingivalis:}

Bacteria incubated anaeropically in blood agar plates for 48 hours and 7-14 days in anaerobic jar at 37C using gas generating kits for carbon dioxide (Micromaster laboratories PVT. LTD 38/39, KalpataruIndEstate,Thane(W) MAH.INDIA .To obtain pure culture the isolate was sub-cultured in Kanamycin blood agar (by dissolving $1.5 \mathrm{~g}$ Kanamycin in $100 \mathrm{ml}$ of sterile water and then mixed with blood agar.

\section{Bacterial identification:- Colony feature:-}

Characterization of bacteria was done based on colony features, size, color, shape and consistency. 


\section{Gram stain:-}

Bacterial film fixed and stained with Triphenylmethane dye, Crystal violet, in conjunction with iodine solution and subsequently treated with an organic solvent as alcohol and counter stained with safranin. Bacteria which retain the dye are designated Gram positive and the gram negative bacteria lose the dye.

\section{Simplfied routine biochemical tests for identification of bacterial isolates:-}

Biochemical tests will be done under anaerobic condition (in anaerobic jar)The biochemical activities of the purified isolates were then studied for identification and confirmation of these organisms. The biochemical tests carried out include Fermentation tests:(Harris,1964).(37) Methyl red tests,Voges-Proskauer test,Indole production test: Hydrogen sulphide production test). Catalase test, Oxidase test:(Cruickshank et al ., 1975, Salle,1961.(38,39) Urease test ( Cheesbrough, 1996).(40) Biochemical tests for P.gingivalis, important characteristics leading to proper identification include, negative oxidase and positive catalase results, negative spot indole results, and the ability to ferment glucose but not lactose.

\section{Culture charcteristics:-}

It grows as white, translucent smooth non-hemolytic colonies in blood agar colonies sticky and adherent $\mathrm{M}$ notfement g/lucose, catalase, heamolysis and urease positive ,oxidase, indole and vogesproskauer negative.

Isolation of prophryomonasegingivalis:-

Bacteria incubated anaeropically in blood agar plates for 48 hours and 7-14 days in anaerobic jar at 37C using gas generating kits for carbon dioxide (Micromaster laboratories PVT. LTD 38/39, KalpataruIndEstate,Thane(W)MAH.INDIA .To obtain pure culture the isolate was sub-cultured in Kanamycin blood agar (by dissolving $1.5 \mathrm{~g}$ Kanamycin in $100 \mathrm{ml}$ of sterile water and then mixed with blood agar.

Microscopical examination showed gram -ve rods .

Biochemical tests:

None of the isolates fermented glucose, All isolates were urease positive, vogesproskaur negative. All isolates were indole -ve, catalase positive and oxidase negative. Some of isolates make gelatin hydrolysis.

\section{Results:-}

Result of Isolation of Actinobacillusactinomycetumocomitans:

Actinobacillusactinomycetumocomitansnot detected in the samples (Negative result)

Result of Isolation of prophryomonasegingivalis

Microscopical examination: Gram negative, short rod

Culture characteristics On blood agar, black hemolytic colonies were seen after 48 hours incubation under anaerobic condition at $37^{\circ} \mathrm{C}$. Sample sub-cultured in blood agar with Kanamycin for 7-14 days anaerobically, colonies changed to brown.

\section{Biochemical tests:-}

Most isolates ferment glucose do not ferment sucrose and lactose,oxidase negative, catalase positive, $\beta$ hemolytic and indole negative

\section{Water garlic extract:-}

Fresh garlic cloves $(100 \mathrm{~g})$ were blended in $20 \mathrm{ml}$ distilled water filtered using cotton wool and ultrafilterd under reduced pressure by using a Buchner funnel and a side armed flask. By subtracting the weight of insoluble material from the weight of the original cloves, the final concentration of garlic extract in solution was determined to be $16.5 \%(\mathrm{w} / \mathrm{v})$. The garlic extract was stored at $-20^{\circ} \mathrm{C}$ and used for antibacterial testing.

In vitro testing of extract for antimicrobial activity:Determination of minimum inhibitory concentration (MIC):-

The antibacterial activity of Allium sativum was evaluated by cup-plate agar diffusion method for aqueous extract. The garlic extract used in present study was $16.5 \%(\mathrm{w} / \mathrm{v})$. One $\mathrm{ml}$ of the standard bacteria suspension were thoroughly mixed with $60 \mathrm{ml}$ of molten sterile Muller Hinton agar media and poured into the petridishes. The agars was left to set and in each of plate cups (10 mm diameter) were cut using a sterile cork borer and agar discs were removed. Garlic extract were prepared in series of increasing concentrations. The bottom of each plat was marked off into 8 segments. Serial dilution from $100 \%,, 50 \%, 25 \%, 12.5 \%$ to $10 \%$ is used. $50 \mu 1$ of extracted garlic 
introduced into the wells using automatic microlitre pipette and all plates were incubated at $37^{\circ} \mathrm{C}$ for 24 hours. Chlorhexidine $0.2 \%$ (Claradine ,Mfd by MEDPHARMA,United Arab Emirates ) used as a positive control, the negative control were distilled water .Sensitivity of P.gingivalisand control was determined by measuring the diameter of the zone of inhibition. The end point (MIC) is the least concentration of antimicrobial agent that completely inhibits the bacterial growth. The resultant growth inhibition zones were measured averaged and the mean values were tabulated. (Table 1).

Table (1) Screening for antibacterial activity of garlic againist the clinical isolates Prophyromonasgingivalis Compared to Chlorhexidine (Mean diameter of of inhibition zone)

\begin{tabular}{|lcc|}
\hline water garlic extract & & \\
Concentration\% & Mean Diameter of zone of inhibition $(\mathrm{mm})$ & negative control (distilled water) \\
\hline $10.0 \%$ & $13.6 \pm 0.51$ & - \\
$12.5 \%$ & $14.2 \pm 0.63$ & - \\
$25.0 \%$ & $15.7 \pm 1.4$ & - \\
$50.0 \%$ & $18.4 \pm 1.26$ & - \\
$100.0 \%$ & $21.5 \pm 1.77$ & $25 \pm 2.2$ \\
\hline Chlorhexidine Digluconate & $0.2 \%$ & \\
\hline
\end{tabular}

Values were expressed as mean \pm S.D.

(-) No growth

The data were carried out using a computer software program (SPSS version 16, Chicago, USA). ANOVA tests were used to identify significant differences between the means of the study groups. Critical $P$ values of significance were set at 0.05 and a confidence of $95 \%$. Pearson Correlation and the value expressed as mean \pm S.D .P value at 0.5

\section{Result:-}

The extract inhibited the growth of P.Gingivalisat concentration of $100 \%, 50 \%, 25 \%, 12.5 \%$ and $10 \%$. The end point(MIC) which is the least concentration of garlic that completely inhibits the growth of P.gingivalis was $10 \%$ .The sensitivity pattern as zone of inhibition $(\mathrm{mm})$ of aqueous garlic extract concentration showed growth inhibition activities against Proyhyromonasgingivaliscompared to sensitivity pattern in ( $\mathrm{mm}$ ) of positive control chlorhexidine $0.2 \%$. The pearson correlation between water garlic extract and chlorhexidine $0.2 \%$ is 0.596 and , $\mathrm{p}$ value $>0.069$, so There was no significance difference between aqueous garlic extract and chlorhexidine $0.2 \%$. No zone of inhibition around the negative controls, ( distilled water ).Table(2)

Table 2

\begin{tabular}{|l|l|l|l|}
\hline & & Garlic water extract & Chlorhexidine \\
\hline Garlic water extract $\quad$ Pearson correlation & 1 & .596 \\
Sig.(2-talied) P. value & & 60 & .069 \\
N & Pearson correlation & .596 & 10 \\
\hline Chlorhexidine & .069 & 1 \\
Sig.(2-talied) P. value & 10 & 10 \\
N & & & \\
\hline
\end{tabular}

*Correlation is significant at the 0.05 level (2 tailed)

$* *$ Correlation is significant at the 0.01 level ( 2 tailed)

Pearson correlation of Garlic and $\quad$ Chlorhexidine $=0.596$

P-Value $=0.069$

\section{Discussion:-}

In the present study Actinobacillus actinomycetumcomitans was not detected so it is in agreement with previous reports which did not support the association of actinobacillus actinomycetumcomitans with aggressive periodontitis; Mohammad Hossein et al (2004), in which no periodontopathogenic bacterial growth was observed in 14 of the samples (6.2\%), Faverir M. ${ }^{\text {et }}$ al (2007) ,José Roberto Cortelli (a)2010 and to some extent with Lau 1 (2004) in which they found that Actinobacillus actinomycetumcomitans was the least recovered micro-organisms from samples taken from patients with aggressive periodontitis. In the present study p.gingivalis was detected in $70 \%$ of 
aggressive periodontitis patients and the result is almost in agreement with the previous studies of Savit E.D.et al (1988) in which the detection was 91\%, Ann L, et al (1998) in which p.gingivalis was detected in $79 \%$ of the patients and in $25 \%$ of healthy subjects. The authors of those studies concluded that P.gingivalis is implicated in the pathogeneses of periodontitis and aggressive periodontitis but P.gingivalis may not be a normal inhabitant of periodontaly healthy subjects.The results are also in agreement with those of Atsuo Amano (1999) in which P.gingivalis was detected in examined sample of 73 patients $(78.5 \%)$ with aggressive periodontitis ,as well as the results of the study by Lau L, et al (2004) in which p.gingivalis was low in healthy subjects and increased in patients with periodontitis. For the prevention and treatment of periodontal diseases a number of topically applied antimicrobial agents were found to inhibit the formation of bacterial plaque and hence, prevents the onset of gingivitis and periodontits. Chlorhexidine gluconate was commonly used in $0.2 \%$ mouthwash or gel. With the rise of bacterial resistance to antibiotics, there is need to search for other antimicrobial agents for treatment and control of oral infections. Garlic which is known to have antibacterial antiviral, anti-brotozoal and antifungal activity (Tariq Abdullah1987).It has an inhibitory effect against gram+ve and gram-ve bacteria in oral cavity (Elnima et al 1983), (Groppo 2002) inhibition of streptococcus mutans(,Bakri 2005) in study of the inhibitory effect on putative periodontal pathogens and (Fanni et al 2007) in study of inhibition of multidrug-resistant strain of streptococcus mutans,so in the present study, which is the first study in Sudan, we confirmed the marked growth inhibition activity of garlic( grows in northern Sudan) against $P$. gingivalis which has been described before (Bakri 2005). Aqueous extract(concentration 16.5\%) at serial dilution of $100 \%, 50 \%, 25 \%, 12.5 \%$ and $10 \%$ showed activity . there was no significant difference between Chlorhexidine gluconate $0.2 \%$, and the aqueous extract, The MIC of the aqueous extracts of garlic in the present study was $10 \%$.

\section{Conclusion:-}

Since garlic water extract in the present study had invitro inhibitory effect on P.gingivalis isolated from the examined group of aggressive periodontitis patients compared to chlohexidine and due to the widespread use of antibiotic and the spread of antibiotic resistance, we present evidence for the antimicrobial activity of garlic extract against $P$.gingivalis and this raises the possibility that garlic may has therapeutic use for prevention and treatment of the onset of aggressive periodontitis.

\section{Recommendation:-}

1-Further laboratory studies on the effectiveness of garlic extract on periodontal pathogens are needed.

2-Preparation of Garlic in dosage forms (mouth wash or local ointment) to be tested on volunteers patients with aggressive periodontitis in carefully designed clinical trials.

\section{Limitation of study:-}

Since allicin is the main biologically active component part of garlic extract and garlic extract showed inhibition for growth of P.gingivalis, so the extracts should be subjected to GC-MS analysis or High Performance Thin Layer Chromatography to determine the amount of allicin .

\section{Competing interests:-}

The authors declare that they have no competing interest.

Financial competing interest.

Al NeelainUniversity partially financing my research .

Authors contribution:-

Professor Ghandour contributed in conception and study design and supervising the study.

Professor Al Nima contributed in laboratory work.

\section{Acknowledgement:-}

The authors acknowledge Dr Raga Eltaype and Mrmudathir (Medicinal and Aromatic Plants Research Institute) and Dr.Shami,

Miss Nosiaba (Department of Microbiology Faculty of Science, Al Neelain University) for their assistance and help. I wish to thank Al Neelain University for sponsoring the scholarship.

\section{References:-}

1. Armitage G C. Development of a classification system for periodontal diseases and conditions. Ann Periodontol 1999; 4: 1-6.1 
2. HaffajeeAD,Cugini MA,D ibartS.Clinical and microbological features of subjects with adult periodontitis who respond poorly to scaling and root planning. J Clin Periodontol,1997; 24:767

3. WennstromJL,HeijlL.Dahlen G. Periodic subgingival antimicrobial irrigation of pockts.1.Clinical observations J Clin Periodontol,1987. 14:541-550

4. SaglieFR,MarfanyA,CamargoP.Intragingivaloccurance of A ctinobacillusactinomycetemcomitans and Bacteroidegingivalis in active destructive periodontal lesions. J periodontol 1988;59:259,

5. Slot J. Salient Biochemical Characters of Actinobacillusactinomycetemcomitans Arch Microbiol.1982 Feb; 131(1):60-7.

6. Alsina M, E. Olle, and J. Frias Improved, Low-Cost Selective Culture Medium for Actinobacillusactinomycetemcomitans J ClinMicrobiol. 2001 February; 39(2): 509-513

7. White D, Mayrand D. Association of oral bacteroides with gingivitis and adult periodontitis. J Periodont Res1981; 16:259-265.

8. ÖzlemYilmaz, Philippe Verbeke, Richard J. Lamont,andDavid M. Ojcius. Intercellular Spreading of Porphyromonasgingivalis Infection in Primary Gingival Epithelial Cells. Infect Immun. 2003 March; 71(3): 1170-1178.

9. Ichiro Nakagawa,AtsuoAmano,MasaeKuboniwa, Takayuki Nakamura,ShigetadaKawabata,andShigeyuki. Hamada.Functional Differences among FimA Variants of Porphyromonasgingivalis and Their Effects on Adhesion to and Invasion of Human Epithelial Cells Infect Immun. 2002 January; 70(1): 277-285.

10. Atsuo Amano, Ichiro Nakagawa, KosukeKataoka, IchijiroMorisaki and ShigeyukiHamada. Distribution of Porphyromonasgingivalis Strains with fimA Genotypes in Periodontitis Patients. Infect Immun. 2002 October; 70(10): 5846-5856.

11. MasaeKuboniwa,Atsuo Amano, Satoshi Shizukuishi, Ichiro Nakagawa, and Shigeyuki Hamada. Specific Antibodies to Porphyromonasgingivalis Lys-Gingipain by DNA Vaccination Inhibit Bacterial Binding to Hemoglobin and Protect Mice from Infection. MicrobiolMolBiol Rev. 1998 December; 62(4): 1244-1263.

12. Fei Yu1, Qing-An Xu2, Weimin Chen1A. targetedfimA DNA vaccine prevents alveolar bone loss in mice after intra-nasal administration Journal of Clinical Periodontology, April 2011; 38, 4, :334-340.

13. Sots J. minocyclin in the treatment of JP. J ClinPeriodontol (1990);17:479.

14. Slots J, Rosling BG Suppression of periodontopathic micro flora in localized juvenile Periodontits by systemic tetracycline .J ClinPeriodontol(1983) ; 10:465-86.

15. Rams TE, Slots J.Antibiotic in periodontal therapy: An up-date. CompendContinEdu Dent; . (1992);13:1130.

16. Rams TE, Feik D, Slots J. Ciprofloxacin /Mitronidazole treatment of recurrent adultPeriodontits. Abstract. J Dent Res(1992); 71:319.

17. M. R. Patters, K. ÅNerud, C. L. Trummel, K. S. Kornman, J. NalbandianandP. B. Robert Inhibition of plaque formation in humans by octenidinemouthrinse.Journal of Periodontal Research , April 1983; 18, (2) : 21221918-

18. Fiotra L, GjermoP,RollGW.ide effect of chlorhexidine mouth wash Scand J Dental Res 1971;79:119-125.

19. DurgaKshitish, Vandana K Laxman.The use of ozonated water and $0.2 \%$ chlorhexidine in the treatment of periodontitis patients: A clinical and microbiologic 2010 .Indian J Dent Res ;21(3):341-348

20. Geisla Mary Silva SoaresI; Luciene Cristina FigueiredoII; Marcelo FaveriII; Sheila CavalcaCortelliIII; Poliana Mendes DuarteII; Magda FeresIV Mechanisms of action of systemic antibiotics used in periodontal treatment and mechanisms of bacterial resistance to these drugs 2012, J. Appl. Oral Sci;20 (3 )Bauru May/June http://dx.doi.org/10.1590/S1678-77572012000300002

21. Meriel G. Jones,Jill Hughes, Angela Tregova, Jonothan Milne, A. Brian Tomsett and Hamish A. Collin. Biosynthesis of the flavour precursors of onion and garlic . 2004. Journal of Experimental Botany ; 55, ( 404 ): 1903-1918.

22. Ross, -Z. M. 'Gara. Hill. E. A. O, D. J Sleightholme, H. V , and Maslin D. J.Antimicrobial Properties of Garlic Oil against Human Enteric Bacteria: Evaluation of Methodologies and Comparisons with Garlic Oil Sulfides and Garlic Powder.Appl Environ Microbiol. 2001 January; 67(1): 475-480.

23. Kyu Hang Kyung, MyungHee Kim, MeeSeung Park, and Youn Soon Kim.Alliinase-Independent Inhibition of Staphylococcus aureusB33 by Heated Garlic .Journal of Food Microbiology and Safety 2004; 67(2):780-785.

24. Uchida Y,TakahashiT,SatoN.The characteristics of antibacterial activity of garlic .Jpn J Antibiot 1975;28:63842

25. SHAHINAZ A,JAVED K,NASIM .A Study of synergistic effect of allicin with antibacterials against microorganisms .ANNALS $2009 ; 15: 138-140$.

26. Elnima EI, Ahmed SA, Mekkawi AG, Mossa JS. The antimicrobial activity of garlic and onion extracts. Pharmazie .1983 Nov;38(11):747-8. 
27. F.C. Groppo, J.C. Ramacciato, R.P. Simões,F.M. Flório, A. Sartoratto. Antimicrobial activity of garlic, tea tree oil, and chlorhexidine against oral microorganisms 2002Int Dent J. ;52(6):433-7

28. I.M. Bakri,C.W.I.Douglas.Inhibitory effect of garlic extract on oral bacteria. Archives of Oral Biology (2005);50:645-651.

29. FaniMM.KohantebJ,DoyoghiM.J.Indion inhibitory activity Of garlic (allium sativum)extraction multidrug resistant streptococcus mutant. Socpedodprev.Dent(2007) J Indian SocPedodPrev Dent. 2007 OctDec;25(4):164-8.

30. Houshmand, Behzad; Mahjour, Faranak; Dianat, Omid .Antibacterial effect of different concentrations of garlic (Allium sativum) extract on dental plaque bacteria. Indian Journal of Dental Research . 2013;24 (1): 71-75.

31. Loesche WJ, SyedSA, SchmidtE,MorrisonEC.Bacterial profiles of subgingival plaques in periodontitis. J Periodontol 1985;56:447-5.

32. SunainaShetty, Biju Thomas, 1 Veena Shetty,2 Rahul Bhandary,3 and Raghavendra M. Shetty4. An in-vitro evaluation of the efficacy of garlic extract as an antimicrobial agent on periodontal pathogens: A microbiological studyAyu. 2013 Oct-Dec; 34(4): 445-451 .

33. FATIH ÖZAN, Muhsin ÖZDEM, Ülkü ÖZAN, Metin ŞENÇIMEN, ZÜBEYDE AKINPOLAT.Evaluation of Cytotoxic effect of Garlic on human gingival fibroblasts: A Preliminary Study Gulhane Med J. 2013; 55(4): 276.

34. Elamin A, Albandar JM, Poulsen K, Ali RW, Bakken V. Prevalence of Aggregatibacteractinomycetemcomitans in Sudanese patients with aggressive periodontitis: a case-control study. J Periodont Res 2011; 46: 285-291.

35. Sillness J, Loe H. Periodontal disease in pregnancy correlation between oral hygiene and periodontal condition. Acta- odontolscand 1964; 22: 121-35.

36. Loe H, Silness J. Periodontal disease and Pregnancy: Prevalence and severity. ActaOdontoScand 1963; 21 : 533551.

37. Haris,MMailiere,Tindal,Cox..Pharmaceutical microbiology..London,W.C 2,England, 1964

38. Cruickshank R.;,Duguid JP, Marmion BP, Swain RH. . Medical Microbiology. Edinburgh,Churchilllivingstone ,1975, 12th Ed.

39. Salle AJ. Fundamental Principal of Bacteriology, , London: McGraw Hill Bookco, UK; 1961. 5th edition

40. Cheesbrough M. Medical Laboratory Manual for Tropical Countries, 14 Bevills close, Paddington, Campridge

41. Mohammad Hossein, Sa, Zainab K. Rate of cultivable subgingival periodontopathogenic bacteria in chronic periodontitis.J Oral Science 2004; 46(3): 157-161.

42. Faverir M. ${ }^{\text {et }}$ al (2007), Faveri M, Mayer MP, Feres M, Dewhirst FE, Paster BJ. Microbiological diversity of generalized aggressive periodontitis by $16 \mathrm{~S}$ rRNA clonal analysis. Oral Microbiol Immunol 2008; 23: 112-118.

43. José Roberto, Davi RA, Caio Vinicies, David Romer. Occurance of Aggregabacter A in Brazilian with chronic periodontitis. Braz OralRes.2010;2:217-223.

44. Lau L, Sanz M, Herrera D, Morillo JM, Martín C. Silva A quantitative real-time polymerase chain reaction versus culture: a comparison between two methods for the detection and quantification of Actinobacillus actinomycetemcomitans, Porphyromonas gingivalis and Tannerella forsythensis in subgingival plaque samples. J Clin Periodontol. 2004 Dec; 31(12): 1061-9.

45. Savitt ED, Strzempko MN, Vaccaro KK, Peros WJ, French CK. Comparison of cultural methods and DNA probe analyses for the detection of Actinobacillus actinomycetemcomitans, bacteroides gingivalis, and bacteroides intermedius in subgingival plaque samples. J Periodontol 1988 Jul; 59(7): 431-8

46. Ann LG, Mitzi RB, Sharon RL, Melvin LM, Eugene JL. Prevalence of porphyromonas gingivalis and periodontal health status. J Clin Microbiol 1998 Nov; 36(11): 3239-3242.

47. A Amano, I Nakagawa, K Kataoka, I Morisaki, S Hamada. Distribution of Porphyromonas gingivalis Strains with fimA Genotypes in Periodontitis Patients. J Clin Microbiol. 1999 May; 37(5): 1426-1430. 